\title{
PARTICIPAÇÃO DAS PRINCIPAIS FRUTAS BRASILEIRAS NO COMÉRCIO INTERNACIONAL: 1997 A 2008 1
}

\author{
GABRIEL BUENO² \& JOSÉ GIACOMO BACCARIN ${ }^{3}$
}

RESUMO - As tendências do mercado mundial de alimentos apontam para alto crescimento no consumo de produtos naturais, como as frutas e verduras. O mercado mundial de frutas frescas registrou, em 2005, cifra superior a US\$ 31,5 bilhões e cresce US\$ 1 bilhão ao ano, em média. Tal fato se reproduz no Brasil, onde se observa elevação do consumo de frutas. Em termos monetários, o valor bruto da produção de frutas no Brasil atingiu, em 2006, cerca de R \$16,3 bilhões, 16,5\% do valor da produção agrícola brasileira. $\mathrm{O}$ presente trabalho buscou analisar características econômicas da participação brasileira no comércio mundial de frutas, entre 1997 e 2008. Ademais, foi analisada a evolução da balança comercial das principais frutas brasileiras, discriminação das exportações em frescas ou processadas, representatividade do comércio externo no valor da produção nacional e participação da exportação de frutas selecionadas na exportação total do agronegócio. Foram utilizados dados da Pesquisa de Orçamento Familiar (POF) do Instituto Brasileiro de Geografia e Estatística; o Sistema de Análise e Levantamento do Comércio Exterior - AliceWeb do Ministério do Desenvolvimento, Indústria e Comércio Exterior e o banco de dados do Ministério da Agricultura, Pecuária e Abastecimento. Após levantamento das frutas que seriam estudadas, constatou-se que o crescimento das exportações foi maior que o crescimento das importações brasileiras de 1997 a 2008. Isso contribuiu para que o seu saldo comercial aumentasse em $112 \%$ no período. As exportações de frutas frescas cresceram relativamente mais que as exportações de frutas processadas. Porém houve queda da participação das exportações de frutas nas exportações do agronegócio brasileiro, de 5,8\%, em 1997, para 3,9\%, em 2008.

Termos para indexação: Comércio exterior; exportação de frutas; balança comercial.

\section{PARTICIPATION OF THE MAIN BRAZILIAN FRUITS IN INTERNATIONAL TRADE FROM 1997 TO 2008}

\begin{abstract}
The current trends in the global food market point to a high growth in consumption of natural products, such as fruits and vegetables. The world market for fresh fruits registered in 2005 cipher exceeding $\$ 31,5$ billion and grows $\$ 1$ billion annum, on averaged. This fact is reproduced in Brazil, which shows increase in fruits consumption. In monetary terms the gross value of fruit production reached, in 2006, around R \$ 16.3 billion, $16.5 \%$ the value of Brazilian agricultural production. The present study sought analyzing economic features of the Brazilian participation in global trade of fruits from 1997 to 2008. Furthermore, it was analyzed the evolution of the trade balance of the main Brazilian fruit, discrimination of exports in fresh or processed fruits, representation of external trade in value of national production and participation of the exports selected fruits in all exportation of the agribusiness. It was used data from the Household Budget Survey from the Brazilian Institute of Geography and Statistics, the system of Survey and Analysis of Foreign Trade - AliceWeb from the Ministry of Development, Industry and Foreign Trade and database from the Ministry of Agriculture, Livestock and Supply. After surveying the fruits that would be studied, it was found that growth of the exports was higher than the growth of Brazilian imports in the period of 1997 to 2008. This contributed to increase the balance trade by $112 \%$ in the period. Exports of fresh fruits grew relatively more than the exports of processed fruits. However there was a drop in the share of fruits export in the Brazilian agribusiness exports, 5.8\%, in 1997, to 3.9\% in 2008.
\end{abstract}

Index terms: Foreign Trade; fruits exports; trade balance.

${ }^{1}$ (Trabalho 278-11). Recebido em: 08-11-2011. Aceito para pubilcação em: 10-04-2012.

${ }^{2}$ Bacharel em Administração de Empresas pela Faculdade de Ciências Agrárias e Veterinárias - Unesp Jaboticabal. E-mail: rrglbueno@ig.com.br

${ }^{3}$ Professor Assistente Doutor do Departamento de Economia Rural - Faculdade de Ciências Agrárias e Veterinárias - Unesp Jaboticabal. E-mail: baccarin@fcav.unesp.br 


\section{INTRODUÇÃO}

As constantes mudanças no padrão alimentar e no comércio internacional decorre da busca por alimentos saudáveis e o crescimento recente da demanda desses alimentos por parte de diversos países, principalmente os desenvolvidos. Ademais, o consumo de frutas, legumes e verduras tem sido associado à diminuição do risco de mortalidade e redução da ocorrência de doenças crônicas (NEUTZLING et al., 2009).

A partir desse cenário, o consumo per capita de frutas frescas no mundo aumentou em $13 \%$, entre 1995 e 2003, alcançando média de $62 \mathrm{~kg} / \mathrm{ano} /$ pessoa (FAO, 2008). Já no período entre 2002 e 2005, o mercado global de frutas cresceu $53 \%$, atingindo o valor de US\$ 51,3 bilhões (BRASIL, 2007).

De acordo com informações da POF/IBGE (2003), citado por Tofanelli et al. (2007), a participação das frutas na alimentação do brasileiro respondia por $24,5 \%$ em 2003, índice considerado baixo em relação a outros países. Porém, pesquisas realizadas em 2010, pelo Ministério da Saúde, revelaram maior presença de frutas e hortaliças no prato dos brasileiros, e tais produtos responderam por $30,4 \%$ da alimentação na população com mais de 18 anos. Deste total, 18,9\% consumiram, em 2009, cerca de cinco porções diariamente, equivalentes a 400 gramas diárias, 2,6 vezes mais que o registrado em 2006 (BRASIL, 2010).

A produção mundial de frutas atingiu 587,6 milhões de toneladas, em 2009. A China liderava o ranking com $19,5 \%$ da produção mundial, seguida pela Índia com $11,6 \%$ e o Brasil com 6,4\%, seguidos por Estados Unidos, Itália, Indonésia, México, Filipinas, Espanha e Turquia. Juntos, estes dez países representaram cerca de $60 \%$ da produção mundial de frutas em 2009 (FAO, 2011).

Apesar de estar entre os 3 maiores produtores mundiais, o Brasil encontrava-se, em 2008, em $15^{\circ}$ no ranking dos exportadores mundiais de frutas. Do total produzido, $47 \%$ foram consumidos in natura $\mathrm{e}$ $53 \%$ foram para processamento. Dentre os $47 \%$ das frutas frescas, apenas $2 \%$ foram exportados e do total processado, $29 \%$ destinaram-se à exportação (ANUÁRIO FRUTICULTURA, 2008).

Nos últimos anos, o Brasil apresentou expressivo crescimento no comércio internacional do agronegócio, consolidando sua posição como um dos maiores produtores e exportadores de alimentos. Poucos países registraram aumento tão significativo no comércio internacional. Esse crescimento expressivo na pauta exportadora de commodities agropecuárias responde por parcela significativa do superávit comercial brasileiro, visto que o Brasil é um dos maiores exportadores mundiais de produtos como: soja, açúcar, carnes, café, entre outros (MATA, 2008). Portanto, é interessante verificar se tal fato vem acontecendo também com as principais frutas produzidas no País.

O presente trabalho tem por objetivos: verificar quais são as principais frutas exportadas e consumidas no Brasil; analisar a balança comercial das respectivas frutas, discriminando as exportações e as importações em frescas e processadas; verificar a participação do comércio internacional no valor da produção nacional, e, por fim, comparar as exportações do conjunto das frutas estudadas com a trajetória de exportações do agronegócio brasileiro.

\section{MATERIAIS E MÉTODOS}

A priori, a pesquisa tem caráter exploratório, e serão abordados aspectos qualitativos e quantitativos dos resultados obtidos. Foram utilizados dados de fontes primárias como: Instituto Brasileiro de Geografia e Estatística (IBGE); Ministério da Agricultura, Pecuária e Abastecimento (MAPA), Banco Nacional do Desenvolvimento Econômico e Social (BNDES), e Ministério do Desenvolvimento, Indústria e Comércio Exterior (MDIC).

Frente ao objetivo do trabalho, o caminho metodológico apresenta 4 etapas: a) identificação das frutas estudadas; b) análise da evolução da balança comercial das frutas estudadas, classificando-as em grupos de frescas ou processadas; c) identificação da representação do comércio exterior frente aos valores da produção de cada cultura; d) levantamento dos dados da exportação do agronegócio e análise da participação das frutas selecionadas nesta pauta exportadora. Em todas as etapas, o período de análise será o de 1997 a 2008.

$\mathrm{Na}$ escolha das principais culturas, foram utilizados dois critérios: as dez principais frutas presentes na cesta de consumo dos brasileiros e as dez frutas que representam maior valor nas exportações brasileiras (somando as formas fresca e processada).

No que tange ao consumo, utilizaram-se dados da Pesquisa de Orçamentos Familiares (POF) de 2002/2003, do Instituto Brasileiro de Geografia e Estatísticas - IBGE, cujo objetivo é de fornecer informações sobre a composição dos orçamentos domésticos, a partir da investigação dos hábitos de consumo (IBGE, 2003). Foram abordados os dados inseridos na POF referentes à "Aquisição alimentar domiciliar per capita anual, no Brasil, segundo os produtos".

No que se refere às principais frutas exporta- 
das em valor, os dados foram fornecidos pelo Sistema Alice Web - Análise das Informações do Comércio Exterior, do MDIC. Foram coletados dados das dez frutas com maior representatividade em valor nas exportações brasileiras, tomando-se a média do triênio 2006/2008. O quadro de 2009 não foi analisado na busca de evitar distorções causadas pela crise financeira internacional, quando as vendas de frutas frescas nacionais, em 2009, caíram 12,1\% em relação a 2008, e a receita, 22,8\% (LOPES, 2010).

As informações do AliceWeb são expressas em dólares americanos (US\$), na condição de venda FOB (Free on Board), e as mercadorias correspondem a todo produto objeto de exportação ou importação. O Brasil passou a utilizar, desde 1996, a Nomenclatura Comum do Mercosul (NCM), baseado no Sistema Harmonizado de Designação e de Codificação de Mercadorias ( $\mathrm{SH}$ ), um método internacional de classificação de mercadorias. Ademais, nesta etapa, foi possível discriminar, junto ao AliceWeb, a pauta exportadora de cada fruta em duas categorias básicas: frescas e processadas.

Posteriormente à escolha e análise da balança comercial das principais frutas brasileiras, foram levantados os dados referentes ao Valor da Produção, em reais, de cada cultura, utilizando-se do acervo das pesquisas do Levantamento Sistemático da Produção Agrícola e da Produção Agrícola Municipal, ambas realizadas pelo IBGE.

Destarte, buscou-se verificar a importância e a representatividade dos valores obtidos no comércio exterior com cada fruta, relacionando os dados da evolução do Valor da Produção nacional frente à trajetória das exportações e importações brasileiras das mesmas, em 1997 e 2008. Para melhor análise comparativa dos valores, somente nesta etapa transformaram-se os valores em dólares do comércio internacional, em reais, pela taxa média anual de câmbio.

Por fim, os dados referentes à exportação do agronegócio foram coletados em arquivos do MAPA, tornando-se possível a comparação da trajetória das exportações das principais frutas frente às exportações do agronegócio.

\section{RESULTADOS E DISCUSSÃO}

De acordo com a POF 2002/2003, quantitativamente, as 10 frutas mais consumidas no Brasil, em 2003, foram: banana, laranja, melancia, mamão, maçã, coco, açaí, tangerina, manga e abacaxi (IBGE, 2003). Já as frutas mais exportadas em valor no triênio 2006/2008, foram: laranja, castanha de caju, uva, melão, manga, maçã, limão, banana, mamão e castanha-do-pará. Destas frutas, 5 enquadravam-se em ambos os grupos, denotando importância no mercado interno e externo: laranja, manga, maçã, banana e mamão. Como não foram encontrados dados específicos do comércio internacional do açaí, esta fruta foi retirada da análise e trabalhou-se com as outras 14 frutas (Tabela 1).

$\mathrm{Na}$ balança comercial, das 14 frutas estudadas entre 1997 e 2008, é possível observar um aumento de $105 \%$ das exportações. Já as importações apresentaram queda até 2002. A partir desse ano, houve retomada das importações, apresentando elevação de 59\% no ${ }^{1}$ período de 1997 a 2008. Por sua vez, o saldo comercial cresceu em $112 \%$, entre 1997 e 2008 (Tabela 2).

Segundo dados obtidos no AliceWeb, algumas culturas apresentaram aumentos expressivos nas exportações (em valor) entre 1997 e 2008: manga (4.730\%, com exportações a partir de 2003); melancia (2.353\%); limão (956\%); melão (627\%); mamão (431\%); uva (411\%) e a maçã (386\%) (Tabela 3).

No que tange a discriminação da pauta exportadora e importadora em frutas frescas e processadas, pode-se observar que o valor das exportações de frutas frescas cresceu a taxas muito superiores ao avanço das exportações de frutas processadas. Destarte, as frutas in natura ganharam espaço na pauta exportadora, passando de 7,5\%, em 1997, para 21,2\%, em 2008, do total exportado de frutas e seus derivados (Tabela 4); (Figura 1).

Ademais, percebe-se que as exportações de frutas frescas não se concentraram em poucos produtos, sendo que, dentre as 14 frutas estudadas, 8 frutas representaram mais de 5\% nas exportações de 1997 a 2008. Destaque para uva, melão, maçã e manga (Tabela 5).

Por sua vez, as exportações de frutas processadas deram-se principalmente por dois produtos principais. O suco de laranja representou mais de $85 \%$ de todo o valor exportado (na forma processada) entre as 14 frutas estudadas. Na soma dos valores exportados de laranja, entre 1997 e 2008, o suco de laranja representou $95 \%$ deste total, sendo o Brasil o maior exportador desta commodity no mundo. A castanha de caju sem casca respondeu por quase $11 \%$ das exportações de frutas processadas, de 1997 a 2008. Banana, manga, melancia, mamão e tangerina não foram exportados na forma processada* (Tabela $6)$.

Já as importações brasileiras das frutas 
apresentaram-se principalmente na forma processada, com crescimento de $122 \%$. As importações das frutas frescas apresentaram queda de 23\%. Quando somados os valores das importações das 14 frutas, também foi possível verificar a diminuição na representatividade das frutas frescas na pauta importadora nacional de $43,6 \%$ para $21,2 \%$, entre 1997 e 2008 (Tabela 7); (figura 1).

Uva e maçã responderam significativamente pela retomada das importações a partir de 2005, sendo que o Brasil aumentou a compra destas frutas em $62,3 \%$ e $53,8 \%$, entre 2005 e 2008.

$\mathrm{Na}$ forma fresca, a maçã foi a fruta mais importada pelo Brasil, seguida da uva. Juntas, estas duas frutas representaram quase $97 \%$ das importações no conjunto das 14 frutas frescas no período de 1997 a 2008. Ainda de acordo com dados coletados, em 1999, o Brasil foi superavitário pela primeira vez na balança comercial da maçã, e o saldo comercial, de negativo em 1997, 1998 e 2001, mostrou-se superavitário em todos os outros anos, apresentando maior saldo em 2008. Ao se analisar o período de 1997 a 2008, a maçã na forma processada obteve aumento em valor nas exportações de $183 \%$, crescimento puxado pelo aumento das vendas de suco de maçã fermentado e não fermentado (Tabela 8).

Uva aparece como produto importante na importação nacional, na sua forma processada, quando comparada às outras frutas pesquisadas, respondendo por $88,3 \%$ das compras no mercado internacional realizadas pelo Brasil (Tabela 9).

A principal razão dos valores negativos no saldo da balança comercial da uva dá-se pelo perfil das importações e exportações brasileiras desta fruta e seus derivados. O Brasil mostra-se deficitário, principalmente quando analisados separadamente vinhos e uvas secas, já que, os primeiros são produtos de altíssimo valor agregado. No que tange aos sucos de uva, o Brasil mostrou-se superavitário quando somados os valores de 1997 a 2008 (US\$ 145,5 milhões contra US\$ 19 milhões importados em uva processada na forma de sucos).

A respeito do valor da produção das culturas estudadas, todas evidenciaram aumento nominal acima de $100 \%$ entre 1997 e 2008. Destaque para o mamão (486\%); manga (419\%); uva (380\%); melão (371\%); laranja (359\%) e castanha de caju (333\%), que tiveram evolução expressiva na renda bruta da produção nacional (Tabela 10). Ao somar o valor da produção, em reais, das 14 frutas estudadas, verificou-se aumento de quase $390 \%$ de 1997 a 2008 , verificando-se crescimento superior à exportação e importação das 14 frutas, e valores superiores em todos os anos analisados (Figura 2).
Algumas frutas apresentaram aumento expressivo de representatividade do comércio internacional sobre o valor da produção. As castanhas (caju e pará), por exemplo, apresentaram valores de exportação maiores que os da produção nacional, o que se deve ao fato do baixo custo da produção/extração do produto e o alto valor agregado que alcançam no mercado externo. A representatividade das exportações de laranja frente à produção $(64,6 \%)$, da maçã $(24,7 \%) \mathrm{e}$ da uva $(23,4 \%)$, em 2008, relata que a exportação de alguns produtos industrializados agrega altos valores, como o caso dos sucos exportados destas três culturas. Destaque também para o melão, em 2008, quando o total exportado ultrapassou o valor da produção, isto porque o próprio processo de melhoria no cultivo da fruta agrega valores altos no comércio internacional. Porém, as outras frutas pesquisadas não mostraram grande representatividade no mercado externo, com baixa participação no Valor da Produção, com potencial pouco explorado nas exportações e voltado quase totalmente ao mercado doméstico.

Por outro lado, as importações do grupo de frutas estudadas não apresentaram representatividade sobre o valor da produção nacional (Figura 2). Destarte, ocorreu diminuição desta representatividade em várias culturas de 1997 a 2008, como é o caso do coco, maçã e uva. Tal fato denota maior eficiência da produção da fruticultura brasileira no âmbito do abastecimento interno (Tabela 11).

Por fim, apesar do avanço das exportações de frutas, este setor não acompanhou o agronegócio brasileiro no mercado internacional, que cresceu $207 \%$ em valor das exportações de1997 a 2008. A participação das principais frutas brasileiras apresentou queda, passando de 5,8\% para 3,9\% do total exportado. Fato que pode ser explicado, entre outras razões, pela necessidade de abastecimento maior do mercado nacional visto as pesquisas recentes do Ministério da Saúde, que relataram aumento do consumo de frutas na mesa dos brasileiros (Tabela 12). 
TABELA 1 - Relação das dez principais frutas consumidas, de acordo com a POF 2002/2003, e mais exportadas entre 2006/2008, em US\$ (FOB).

\begin{tabular}{ccccc}
\hline & \multicolumn{2}{c}{ POF 2002/2003 } & \multicolumn{2}{c}{ Média Exportação 200/2008 } \\
\hline Classificação & Frutas & Consumo per capita anual (kg) & Frutas & Valor FOB (US\$) \\
$1^{\text {a }}$ & Banana & 7,0 & Laranja & 1.991 .528 .107 \\
$2^{\text {a }}$ & Laranja & 4,6 & Castanha de caju & 202.936 .787 \\
$3^{\text {a }}$ & Melancia & 2,4 & Uva & 167.496 .657 \\
$4^{\text {a }}$ & Mamão & 1,8 & Melão & 122.862 .421 \\
$5^{\text {a }}$ & Maçã & 1,6 & Manga & 98.503 .427 \\
$6^{\text {a }}$ & Cocos & 1,5 & Maçã & 89.051 .811 \\
$7^{\text {a }}$ & Açaí & 1,2 & Limão & 46.962 .823 \\
$8^{\text {a }}$ & Tangerina & 1,1 & Banana & 39.504 .592 \\
$9^{\text {a }}$ & Manga & 0,8 & Mamão & 34.465 .972 \\
$10^{\text {a }}$ & Abacaxi & 0,8 & Castanha-do-pará & 21.618 .387 \\
\hline
\end{tabular}

Fonte: IBGE 2002-2003 e AliceWeb/MDIC - 2010.

TABELA 2 - Balança Comercial das principais frutas brasileiras, em US\$ (FOB), 1997 a 2008.

\begin{tabular}{ccccccc}
\hline Ano & \multicolumn{2}{c}{ Exportação } & \multicolumn{2}{c}{ Importação } & \multicolumn{2}{c}{ Saldo Comercial } \\
\hline & Valor & Indice & Valor & Indice & Valor & Índice \\
\hline $\mathbf{1 9 9 7}$ & $1.354,8$ & 100 & 193,1 & 100 & $1.161,8$ & 100 \\
$\mathbf{1 9 9 8}$ & $1.566,2$ & 116 & 193,1 & 100 & $1.373,2$ & 118 \\
$\mathbf{1 9 9 9}$ & $1.575,4$ & 116 & 156,6 & 81 & $1.418,8$ & 122 \\
$\mathbf{2 0 0 0}$ & $1.422,0$ & 105 & 142,1 & 74 & $1.280,0$ & 110 \\
$\mathbf{2 0 0 1}$ & $1.185,5$ & 88 & 142,9 & 74 & $1.042,6$ & 90 \\
$\mathbf{2 0 0 2}$ & $1.424,8$ & 105 & 106,1 & 55 & $1.318,8$ & 114 \\
$\mathbf{2 0 0 3}$ & $1.711,3$ & 126 & 114,5 & 59 & $1.596,9$ & 138 \\
$\mathbf{2 0 0 4}$ & $1.739,7$ & 128 & 143,6 & 74 & $1.596,2$ & 137 \\
$\mathbf{2 0 0 5}$ & $1.881,0$ & 139 & 174,8 & 91 & $1.706,2$ & 147 \\
$\mathbf{2 0 0 6}$ & $2.091,7$ & 154 & 237,8 & 123 & $1.853,9$ & 160 \\
$\mathbf{2 0 0 7}$ & $3.042,9$ & 225 & 279,7 & 145 & $2.763,1$ & 238 \\
$\mathbf{2 0 0 8}$ & $2.773,9$ & 205 & 306,3 & 159 & $2.467,6$ & 212 \\
\hline
\end{tabular}

Fonte: MDIC - AliceWeb 2010.

TABELA 3 - Desempenho das exportações das frutas em 1997 e 2008, em valor, US\$ (FOB).

\begin{tabular}{cccc}
\hline Cultura & Exp. 1997 & Exp. 2008 & (\%) $\mathbf{1 9 9 7 / 2 0 0 8}$ \\
\hline Manga & $2.457 .716^{*}$ & 118.703 .985 & 4730 \\
\hline Melancia & 739.441 & 18.141 .871 & 2353 \\
Limão & 5.153 .696 & 54.418 .186 & 956 \\
Melão & 20.913 .101 & 152.132 .031 & 627 \\
Mamão & 7.281 .036 & 38.637 .044 & 431 \\
Uva & 38.165 .211 & 195.066 .287 & 411 \\
Maçã & 24.132 .560 & 117.265 .756 & 386 \\
Abacaxi & 5.326 .173 & 24.522 .186 & 360 \\
Banana & 8.382 .281 & 35.657 .717 & 325 \\
Laranja (com sucos) & 1.056 .730 .720 & 1.796 .771 .894 & 70 \\
Cocos & 308.816 & 428.322 & 39 \\
Castanha de caju & 156.917 .101 & 196.074 .102 & 25 \\
Tangerina & 4.692 .680 & 5.775 .972 & 23 \\
Castanha-do-pará & 26.075 .115 & 20.319 .491 & -22 \\
\hline Total & 1.357 .275 .647 & 2.773 .914 .844 & 105
\end{tabular}

Fonte: MDIC - AliceWeb 2010.

* valor de 2003, quando começa a exportação de manga. 
TABELA 4 - Evolução das exportações do conjunto das 14 frutas, divididas em frescas e processadas, 1997-2008, US\$ (FOB).

\begin{tabular}{|c|c|c|c|c|c|c|c|}
\hline Ano & Frescas (1) & Índice & Processadas (2) & Índice & Total (3) & $1 / 3(\%)$ & $2 / 3(\%)$ \\
\hline 1997 & 102.215 .327 & 100 & 1.252 .602 .604 & 100 & 1.354 .817 .931 & 7,5 & 92,5 \\
\hline 1998 & 96.516 .327 & 94 & 1.469 .727 .925 & 117 & 1.566 .244 .252 & 6,2 & 93,8 \\
\hline 1999 & 135.314 .431 & 132 & 1.440 .043 .822 & 115 & 1.575 .358 .253 & 8,6 & 91,4 \\
\hline 2000 & 145.017 .368 & 142 & 1.277 .001 .464 & 102 & 1.422 .018 .832 & 10,2 & 89,8 \\
\hline 2001 & 169.904 .612 & 166 & 1.015 .631 .548 & 81 & 1.185 .536 .160 & 14,3 & 85,7 \\
\hline 2002 & 198.226 .466 & 194 & 1.226 .604 .108 & 98 & 1.424 .830 .574 & 13,9 & 86,1 \\
\hline 2003 & 269.315 .060 & 263 & 1.442 .032 .244 & 115 & 1.711 .347 .304 & 15,7 & 84,3 \\
\hline 2004 & 371.496 .680 & 363 & 1.368 .243 .985 & 109 & 1.739 .740 .665 & 21,4 & 78,6 \\
\hline 2005 & 449.940 .228 & 440 & 1.431 .090 .307 & 114 & 1.881 .030 .535 & 23,9 & 76,1 \\
\hline 2006 & 477.680 .292 & 467 & 1.613 .996 .085 & 129 & 2.091 .676 .377 & 22,8 & 77,2 \\
\hline 2007 & 645.417 .022 & 631 & 2.397 .466 .140 & 191 & 3.042 .883 .162 & 21,2 & 78,8 \\
\hline 2008 & 720.904 .730 & 705 & 2.053 .010 .114 & 164 & 2.773 .914 .844 & 26,0 & 74,0 \\
\hline
\end{tabular}

TABELA 5 - Participação nas exportações acumuladas de frutas frescas, 1997 a 2008, US\$ (FOB).

\begin{tabular}{ccccc}
\hline Posição & Cultura & Exp.1997-2008 & (\%) $\mathbf{1 9 9 7 - 2 0 0 8}$ & (\%) Acumulado \\
\hline $1^{\circ}$ & Uva & 769.048 .579 & 20,3 & 20,3 \\
$2^{\text {o }}$ & Melão & 761.723 .139 & 20,1 & 40,4 \\
$3^{\text {o }}$ & Maçã & 465.040 .380 & 12,3 & 52,7 \\
$4^{\text {o }}$ & Manga* & 433.629 .483 & 11,4 & 64,2 \\
$5^{\circ}$ & Banana & 304.006 .774 & 8,0 & 72,2 \\
$6^{\circ}$ & Mamão & 285.836 .399 & 7,5 & 79,8 \\
$7^{\circ}$ & Limão & 212.305 .198 & 5,6 & 85,4 \\
$8^{\circ}$ & Laranja & 207.600 .613 & 5,4 & 90,9 \\
$9^{\circ}$ & Castanha-do-pará & 131.539 .691 & 3,4 & 94,4 \\
$10^{\circ}$ & Abacaxi & 77.723 .059 & 2,0 & 96,4 \\
$11^{\circ}$ & Tangerina & 66.168 .251 & 1,7 & 98,2 \\
$12^{\circ}$ & Melancia & 65.234 .619 & 1,7 & 99,9 \\
$13^{\circ}$ & Coco & 1.560 .480 & 0,0 & 99,9 \\
$14^{\circ}$ & Castanha de caju & 531.878 & 0,0 & 100,0 \\
\hline TOTAL & & $\mathbf{3 . 7 8 1 . 9 4 8 . 5 4 3}$ & 100,0 & - \\
\hline
\end{tabular}

Fonte: MDIC - AliceWeb 2010 *exportação de manga a partir de 2003.

TABELA 6 - Participação das exportações acumuladas de frutas processadas*, 1997 a 2008, US\$ (FOB).

\begin{tabular}{ccccc}
\hline Posição & Cultura & Exp. 1997-2008 & (\%) 1997-2008 & (\%) Acumulado \\
\hline $1^{\circ}$ & Laranja & 15.361 .491 .869 & 85,4 & 85,4 \\
$2^{\text {o }}$ & Castanha de caju & 1.950 .148 .935 & 10,8 & 96,2 \\
$3^{\circ}$ & Maçã & 221.099 .520 & 1,2 & 97,5 \\
$4^{\circ}$ & Uva & 210.127 .077 & 1,2 & 98,6 \\
$5^{\circ}$ & Castanha-do-pará & 110.197 .507 & 0,6 & 99,3 \\
$6^{\circ}$ & Abacaxi & 82.948 .896 & 0,5 & 99,7 \\
$7^{\text {o }}$ & Limão & 47.974 .724 & 0,3 & 100,0 \\
$8^{\circ}$ & Coco & 3.365 .880 & 0,0 & 100,0 \\
$9^{\text {o }}$ & Mamão & 95.938 & 0,0 & - \\
\hline TOTAL & & $\mathbf{1 7 . 9 8 7 . 4 5 0 . 3 4 6}$ & 100,0 & - \\
\hline
\end{tabular}

Fonte: MDIC - AliceWeb 2010 *banana, manga, melancia, melão e tangerina não foram exportadas na forma processada. 
TABELA 7 - Evolução das importações do conjunto das 14 frutas (em frescas e processadas), 1997-2008, US\$ (FOB).

\begin{tabular}{cccccccc}
\hline Ano & Frescas (1) & Índice & \multicolumn{2}{c}{ Processadas (2) Índice } & Total (3) & $\mathbf{1 / 3}(\mathbf{\%})$ & $\mathbf{2 / 3}(\mathbf{\%})$ \\
\hline $\mathbf{1 9 9 7}$ & 84.130 .211 & 100 & 108.932 .852 & 100 & 193.063 .063 & 43,6 & 56,4 \\
$\mathbf{1 9 9 8}$ & 87.916 .295 & 105 & 105.137 .848 & 97 & 193.054 .143 & 45,5 & 54,5 \\
$\mathbf{1 9 9 9}$ & 36.909 .773 & 44 & 119.656 .295 & 110 & 156.566 .068 & 23,6 & 76,4 \\
$\mathbf{2 0 0 0}$ & 30.952 .067 & 37 & 111.108 .487 & 102 & 142.060 .554 & 21,8 & 78,2 \\
$\mathbf{2 0 0 1}$ & 35.940 .265 & 43 & 106.953 .911 & 98 & 142.894 .176 & 25,2 & 74,8 \\
$\mathbf{2 0 0 2}$ & 25.951 .077 & 31 & 80.118 .521 & 74 & 106.069 .598 & 24,5 & 75,5 \\
$\mathbf{2 0 0 3}$ & 21.376 .397 & 25 & 93.097 .719 & 85 & 114.474 .116 & 18,7 & 81,3 \\
$\mathbf{2 0 0 4}$ & 22.125 .860 & 26 & 121.462 .010 & 112 & 143.587 .870 & 15,4 & 84,6 \\
$\mathbf{2 0 0 5}$ & 37.974 .059 & 45 & 136.839 .402 & 126 & 174.813 .461 & 21,7 & 78,3 \\
$\mathbf{2 0 0 6}$ & 54.520 .291 & 65 & 183.280 .310 & 168 & 237.800 .601 & 22,9 & 77,1 \\
$\mathbf{2 0 0 7}$ & 60.061 .781 & 71 & 219.677 .749 & 202 & 279.739 .530 & 21,5 & 78,5 \\
$\mathbf{2 0 0 8}$ & 64.972 .139 & 77 & 241.328 .713 & 222 & 306.300 .852 & 21,2 & 78,8 \\
\hline
\end{tabular}

Fonte: MDIC - AliceWeb 2010.

TABELA 8 - Participação das importações acumuladas de frutas frescas entre 1997-2008, US\$ (FOB).

\begin{tabular}{ccccc}
\hline Posição & Cultura & Imp. 1997-2008 & $\mathbf{( \% )} \mathbf{1 9 9 7 - 2 0 0 8}$ & $\mathbf{( \% )}$ Acumulado \\
\hline $1^{\circ}$ & Maçã & 402.102 .554 & 71,44 & 71,44 \\
\hline $2^{\circ}$ & Uva & 142.102 .313 & 25,25 & 96,69 \\
\hline $3^{\circ}$ & Tangerina & 8.201 .137 & 1,46 & 98,15 \\
\hline $4^{\circ}$ & Laranja & 7.224 .180 & 1,28 & 99,43 \\
\hline $5^{\circ}$ & Limão & 1.403 .400 & 0,25 & 99,68 \\
\hline $6^{\circ}$ & Coco & 1.125 .227 & 0,20 & 99,88 \\
\hline $7^{\circ}$ & Banana & 241.994 & 0,04 & 99,92 \\
\hline $8^{\circ}$ & Abacaxi & 223.973 & 0,04 & 99,96 \\
\hline $9^{\circ}$ & Melão & 166.459 & 0,03 & 99,99 \\
\hline $10^{\circ}$ & Manga & 22.277 & 0,004 & 100,00 \\
\hline $11^{\circ}$ & Melancia & 16.701 & 0,003 & 100,00 \\
\hline TOTAL & & $\mathbf{5 6 2 . 8 3 0 . 2 1 5}$ & 100,00 & -
\end{tabular}

Fonte: MDIC - AliceWeb 2010 * castanha de caju, castanha do Pará e mamão não foram importadas na forma fresca

TABELA 9 - Evolução das exportações do conjunto das 14 frutas, divididas em frescas e processadas, 1997-2008, US\$ (FOB).

\begin{tabular}{|c|c|c|c|c|}
\hline Posição & Cultura & Imp. 1997-2008 & (\%) 1997-2008 & (\%) Acumulado \\
\hline $1^{\mathrm{o}}$ & Uva (vinho/uva-passa) & 1.438 .495 .707 & 88,38 & 88,3 \\
\hline $2^{\circ}$ & Coco & 78.468 .574 & 4,82 & 93,2 \\
\hline $3^{\circ}$ & Limão & 71.369 .991 & 4,39 & 97,5 \\
\hline $4^{\mathrm{o}}$ & Laranja & 24.488 .510 & 1,50 & 99,1 \\
\hline $5^{\circ}$ & Abacaxi & 6.413 .360 & 0,39 & 99,5 \\
\hline $6^{\circ}$ & Maçã & 6.041 .375 & 0,37 & 99,8 \\
\hline $7^{\circ}$ & Castanha-do-pará & 1.094 .506 & 0,07 & 99,9 \\
\hline $8^{\circ}$ & Castanha de caju & 1.009 .546 & 0,06 & 99,9 \\
\hline $9^{\circ}$ & Mamão & 212.248 & 0,01 & 100,0 \\
\hline
\end{tabular}

Fonte: MDIC-AliceWeb 2010 *banana, manga, melancia, melão e tangerina não foram importadas na forma processada. 
TABELA 10 - Exportação e Valor da Produção das 14 frutas em 1997 e 2008 em R\$.

\begin{tabular}{lcccccc}
\hline Cultura & Exp (1) - 1997 & Exp (1') - 2008 & VP(2) - 1997 & VP(2') - 2008 & $\mathbf{1 / 2}(\mathbf{\%})$ & $\mathbf{1}^{\prime} / \mathbf{2}^{\prime}(\mathbf{\%})$ \\
\hline Abacaxi & 5.741 .614 & 44.988 .402 & 322.939 .000 & 1.038 .687 .000 & 1,8 & 4,3 \\
Banana & 9.036 .099 & 65.417 .648 & 895.306 .000 & 3.165 .312 .000 & 1,0 & 2,0 \\
Cast. caju & 169.156 .635 & 359.717 .548 & 50.251 .000 & 217.460 .000 & 336,6 & 165,4 \\
Cast.-pará & 28.108 .974 & 37.278 .138 & 2.053 .000 & 4.161 .000 & $1.369,2$ & 895,9 \\
Coco & 332.904 & 785.800 & 243.448 .000 & 799.744 .000 & 0,1 & 0,1 \\
Laranja & 1.139 .155 .716 & 3.296 .357 .717 & 1.111 .698 .000 & 5.100 .062 .000 & 102,4 & 64,6 \\
Limão & 5.555 .684 & 99.835 .604 & 160.167 .000 & 366.763 .000 & 3,5 & 27,2 \\
Maçã & 26.014 .900 & 215.135 .756 & 300.872 .000 & 872.625 .000 & 8,6 & 24,7 \\
Mamão & 7.848 .957 & 70.883 .521 & 179.862 .000 & 1.021 .821 .000 & 4,4 & 6,9 \\
Manga & 0 & 217.774 .331 & 147.608 .000 & 765.376 .000 & 0,0 & 28,5 \\
Melancia & 797.117 & 33.283 .077 & 149.539 .000 & 601.960 .000 & 0,5 & 5,5 \\
Melão & 22.544 .323 & 279.101 .424 & 54.670 .000 & 257.515 .000 & 41,2 & 108,4 \\
Tangerina & 5.058 .709 & 10.596 .598 & 228.080 .000 & 478.106 .000 & 2,2 & 2,2 \\
Uva & 41.142 .097 & 357.868 .610 & 318.049 .000 & 1.527 .395 .000 & 12,9 & 23,4 \\
\hline TOTAL & 1.460 .493 .729 & 5.089 .024 .174 & 4.164 .542 .000 & 16.216 .987 .000 & 35,0 & 31,4 \\
\hline
\end{tabular}

Fonte: MDIC Alice Web / IBGE Sidra - 2010.

TABELA 11 - Importação e Valor da Produção das 14 frutas em 1997 e 2008 em R\$.

\begin{tabular}{lcccccc}
\hline Cultura & Imp (1) - 1997 & Imp (1') - 2008 & VP(2) - 1997 & VP(2') - 2008 & $\mathbf{1} / \mathbf{2}(\%)$ & $\mathbf{1}^{\prime} / \mathbf{2} '(\%)$ \\
\hline Abacaxi & 1.946 .266 & 539.950 & 322.939 .000 & 1.038 .687 .000 & 0,6 & 0,1 \\
Banana & 687 & 26.394 & 895.306 .000 & 3.165 .312 .000 & 0,0 & 0,0 \\
Cast. caju & 141.320 & 928.487 & 50.251 .000 & 217.460 .000 & 0,3 & 0,4 \\
Cast.-pará & 141.320 & 928.487 & 2.053 .000 & 4.161 .000 & 6,9 & 22,3 \\
Coco & 19.639 .901 & 10.471 .647 & 243.448 .000 & 799.744 .000 & 8,1 & 1,3 \\
Laranja & 2.425 .333 & 5.261 .081 & 1.111 .698 .000 & 5.100 .062 .000 & 0,2 & 0,1 \\
Limão & 1.496 .292 & 19.356 .127 & 160.167 .000 & 366.763 .000 & 0,9 & 5,3 \\
Maçã & 61.290 .531 & 88.901 .017 & 300.872 .000 & 872.625 .000 & 20,4 & 10,2 \\
Mamão & 225.038 & 679 & 179.862 .000 & 1.021 .821 .000 & 0,1 & 0,0 \\
Manga & 0 & 33.557 & 147.608 .000 & 765.376 .000 & 0,0 & 0,0 \\
Melancia & 6.199 & 0 & 149.539 .000 & 601.960 .000 & 0,0 & 0,0 \\
Melão & 50.158 & 46.507 & 54.670 .000 & 257.515 .000 & 0,1 & 0,0 \\
Tangerina & 1.500 .350 & 1.524 .065 & 228.080 .000 & 478.106 .000 & 0,7 & 0,3 \\
Uva & 119.258 .587 & 433.921 .544 & 318.049 .000 & 1.527 .395 .000 & 37,4 & 28,4 \\
TOTAL & 208.121 .982 & 561.939 .542 & 4.164 .542 .000 & 16.216 .987 .000 & 4,9 & 3,4 \\
\hline
\end{tabular}

Fonte: MDIC Alice Web / IBGE Sidra - 2010.

TABELA 12 - Exportação das 14 frutas, do agronegócio e respectiva participação, 1997 a 2008, em US\$.

\begin{tabular}{cccccc}
\hline Ano & 14 Frutas (1) & Índice & Agronegócio (2) & Índice & $\mathbf{1 / 2}$ \\
\hline $\mathbf{1 9 9 7}$ & 1.354 .817 .931 & 100 & 23.366 .542 .184 & 100 & 5,8 \\
$\mathbf{1 9 9 8}$ & 1.566 .244 .252 & 116 & 21.546 .135 .631 & 92 & 7,2 \\
$\mathbf{1 9 9 9}$ & 1.575 .358 .253 & 116 & 20.494 .004 .752 & 88 & 7,6 \\
$\mathbf{2 0 0 0}$ & 1.422 .018 .832 & 105 & 20.593 .721 .783 & 88 & 6,9 \\
$\mathbf{2 0 0 1}$ & 1.185 .536 .160 & 88 & 23.857 .248 .907 & 102 & 4,9 \\
$\mathbf{2 0 0 2}$ & 1.424 .830 .574 & 105 & 24.839 .934 .791 & 106 & 5,7 \\
$\mathbf{2 0 0 3}$ & 1.711 .347 .304 & 126 & 30.645 .283 .859 & 131 & 5,5 \\
$\mathbf{2 0 0 4}$ & 1.739 .740 .665 & 128 & 39.029 .308 .891 & 167 & 4,4 \\
$\mathbf{2 0 0 5}$ & 1.881 .030 .535 & 139 & 43.617 .046 .992 & 187 & 4,3 \\
$\mathbf{2 0 0 6}$ & 2.091 .676 .377 & 154 & 49.464 .943 .808 & 212 & 4,2 \\
$\mathbf{2 0 0 7}$ & 3.042 .883 .162 & 225 & 58.420 .418 .802 & 250 & 5,2 \\
$\mathbf{2 0 0 8}$ & 2.773 .914 .844 & 205 & 71.806 .467 .218 & 307 & 3,8 \\
\hline
\end{tabular}

Fonte: MDIC -Alice Web 2010 e MAPA 2010 


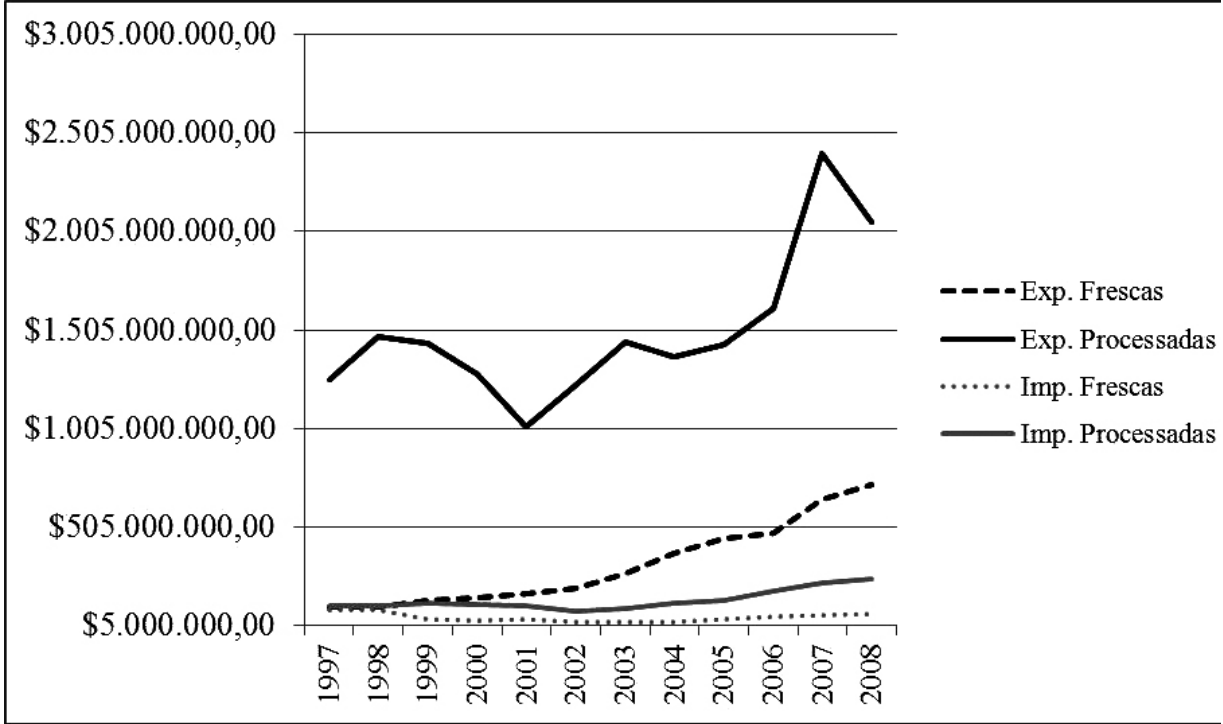

FIGURA 1 - Exportação e Importação do conjunto das 14 frutas, em fresca e processada, de 1997 a 2008 , em US\$ (FOB).

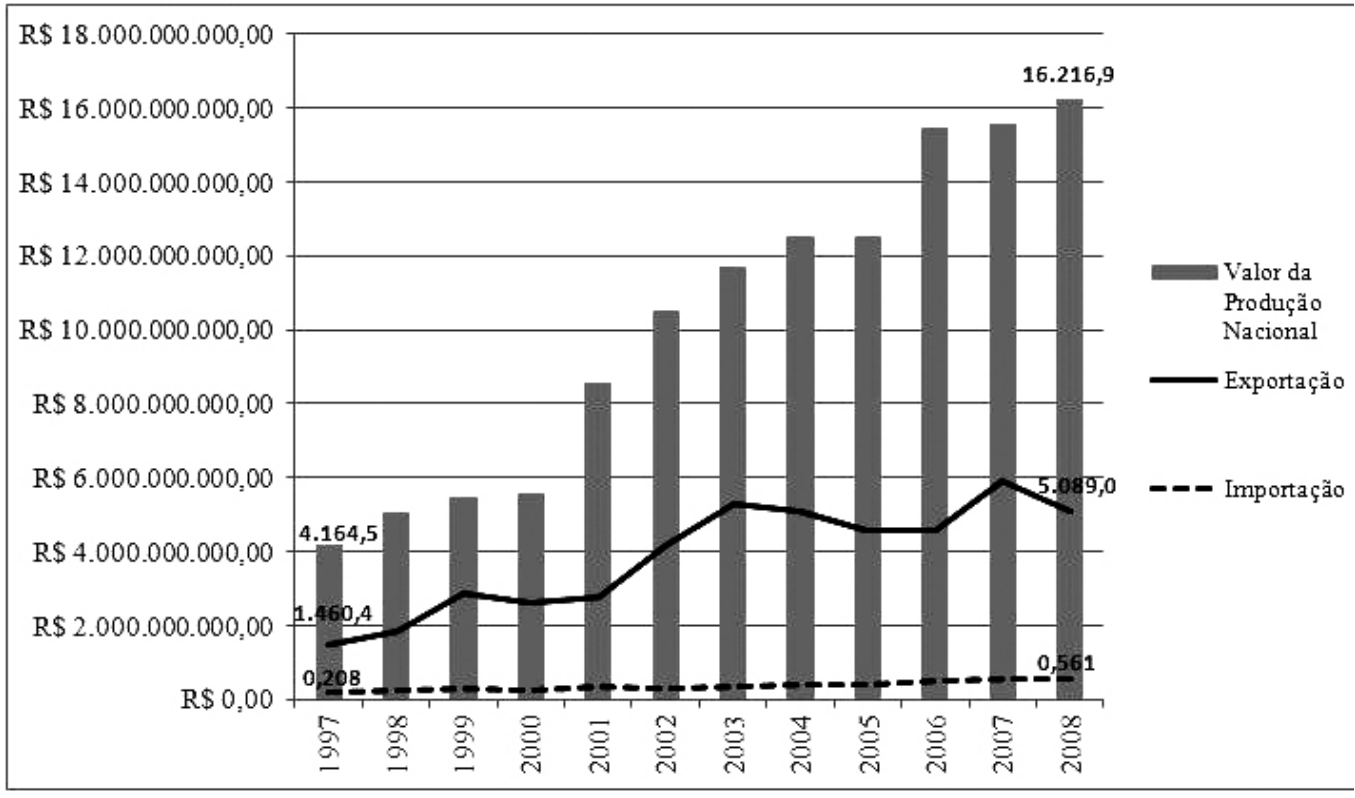

FIGURA 2 - Valor da Produção Nacional, exportação e importação do conjunto das 14 frutas de 1997 a 2008, em R\$. 


\section{CONCLUSÃO}

1-Foi constatado que o avanço das exportações das 14 frutas analisadas no trabalho não acompanhou o desempenho das exportações do agronegócio brasileiro. Por conseguinte, a representatividade do conjunto das frutas estudadas na pauta da exportação do agronegócio caiu de 5,8\%, em 1997, para 3,9\%, em 2008.

2-Entretanto, as exportações das 14 frutas apresentaram aumento, em valor, de aproximadamente $105 \%$ no período entre 1997 e 2008 . Já, as importações mostraram aumento de $59 \%$. As exportações saltaram de US\$ 1,35 bilhão em 1997, para US\$ 2,77 bilhões, em 2008. Foram exportados, entre 1997 e 2008 , US\$ 21,76 bilhões. Desse valor total, o suco de laranja foi responsável por $68,2 \%$ das exportações das 14 frutas estudadas, entre 1997 e 2008.

3-No que diz respeito às exportações, as 14 frutas na forma fresca apresentaram um salto em valor de aproximadamente $605 \%$, passando de US\$ 102,2 milhões em 1997 para US\$ 720,9 milhões em 2008. Com isso, a participação das frutas frescas na exportação do conjunto das frutas estudadas passou de $7,5 \%$ para $26,0 \%$ no mesmo período.

4-A exportação na forma processada apresentou aumento, em valor, de $64,0 \%$, passando de US\$ 1,25 bilhão em 1997 para 2,05 bilhões em 2008. Entretanto, as exportações das frutas na forma processada mostraram-se muito concentradas, sendo que o suco de laranja e a castanha de caju sem casca responderam, respectivamente, por $85,4 \%$ e $10,8 \%$ do total exportado. Frente ao maior avanço das exportações brasileiras de frutas frescas, a participação das processadas, na pauta das exportações das 14 frutas, caiu de $92,5 \%$ para $74,0 \%$ no período compreendido na pesquisa.

5-Já as importações brasileiras saltaram de US\$ 193 milhões em 1997 para US\$ 306 milhões em 2008. As compras ocorreram, principalmente, na forma de frutas processadas, sendo que este grupo, em 1997, representava 56,4\% das importações nacionais de frutas e, em 2008, respondeu por 78,8\%.

6-No que se refere à participação das exportações no Valor da Produção nacional, observou-se aumento de representatividade e ganho de importância do mercado externo.
7-Portanto, ficou claro o avanço do Brasil nas exportações de frutas, principalmente na forma fresca, já que o consumo das frutas em sua forma in natura é uma tendência no mercado internacional, o que mostra um cenário com perspectivas favoráveis. O processo de melhoria da qualidade da produção das frutas frescas já representa a agregação de valor ao produto no comércio mundial.

8-Sendo assim, por se apresentar como terceiro maior produtor mundial, a fruticultura brasileira tem um potencial enorme para expandir sua participação no mercado internacional, ora mantendo o desempenho das exportações das principais frutas frescas presentes na pesquisa, ora na divulgação de outras frutas exóticas no mercado internacional ou na busca pela diversificação das exportações de outras frutas na forma processada.

\section{REFERÊNCIAS}

ANUÁRIO BRASILEIRO DE FRUTICULTURA 2008. São Paulo: Ed. Gazeta, 2008. p. 136.

BRASIL. Ministério da Saúde. Disponível em: $<$ http://portal.saude.gov.br/portal/aplicacoes/noticias/default.cfm?pg $=$ dspDetalheNoticia\&id area $=124 \& C O \_$NOTICIA $=11227>$. Acesso em: 20 maio 2010.

BRASIL. Ministério do Desenvolvimento, Indústria e Comércio. Secretaria de Comércio Exterior - SECEX. Base de dados ALICE-Web. Disponível em: $<$ http://aliceweb.desenvolvimento.gov.br/>.

BRASIL. Ministério da Agricultura, Pecuária e Abastecimento. Cadeia produtiva de frutas. Brasília: IICA. 2007. (Série agronegócios, 7). Disponível em: <http://www.ibraf.org.br/x_files/Documentos/ Cadeia_Produtiva_de_Frutas_S\%C3\%A9rie_ Agroneg\%C3\%B3cios_MAPA.pdf>. Acesso em: 15 maio 2010.

FAO - Food and Agriculture Organization of the United Nation. Codex Committee on fresh fruits and vegetables. Mexico City: Comission del Codex Alimentarius, 2011. Disponível em: $\leq \mathrm{ftp}: / / \mathrm{ftp}$.fao. org/codex/ccffv16/ff16 11e.pdf>. Acesso em: 09 out. 2011. 
FAO- Food and Agriculture Organization of United Nations. Current situation and medium-term outlook for tropical fruits. Diaponível em: $<$ http://www.fao. org/ES/ESC/en/15/217/highlight 218.html >. Acesso em: maio 2009.

IBGE - Instituto Brasileiro de Geografia e Estatística. 2003. Disponível em: <http://www.ibge. gov.br/home/estatistica/populacao/condicaodevida/ pof/2002aquisicao/tab11.pdf $>$. Acesso em: 20 jul. 2010 .

LOPES, F. Exportação: estudo aponta países-alvos para frutas brasileiras. Valor Econômico, abr., 2010. Disponível em: <www.global21.com.br/materias/

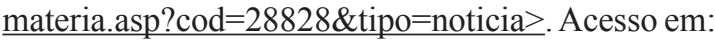
01 abr. 2010.
MATA, D. da; FREITAS, R.E. Produtos agropecuários: para quem exportar? Revista de Economia e Sociologia Rural, Brasília, v.46, n.2, p.257-290, 2008.

NEUTZLING, M. B.; ROMBALDI, A. J.; AZEVEDO, M. R.; HALLAL, P.C. Fatores associados ao consumo de frutas, legumes e verduras em adultos de uma cidade no Sul do Brasil. Caderno de Saúde Pública, Rio de Janeiro, v.25, n.11, p.2365-2374, 2009.

TOFANELLI, M.B.S.; FERNANDES, M.de S.; CARRIJO, N.S.; MARTINS FILHO, O. B. Mercado de frutas frescas no município de Mineiros-GO. Revista Brasileira de Fruticultura, Jaboticabal, v.29, n.2, p.282-286, 2007. 